\title{
The Additional Precision Provided by Region-Specific Data: the Identification of Fuel-Use and Pollution Generation Coefficients in the Jersey Economy ${ }^{1}$ \\ Forthcoming in Regional Studies, June 06
}

\begin{abstract}
Karen Turner*
* Fraser of Allander Institute and Department of Economics, University of Strathclyde, Glasgow, UK
\end{abstract}

\begin{abstract}
:
A debate is currently ongoing in the UK regarding the need to collect and report data at the regional level. One specific area of this debate is the extent to which region-specific economic and environmental data are required to carry out analyses of devolved sustainability policy issues. In this paper I use the Jersey economy as a case study to assess the added precision that is gained from using good quality region-specific data compared to adjusted national UK data. I find that, due to differences in polluting technology between Jersey and the UK, estimates based on national emissions intensities produce results that are misleading in terms of both absolute pollution levels and the relative contribution of different activities to total emissions in the economy. While Jersey may be regarded as atypical in many ways relative to other UK regions, I argue that the results of this study show that regional environmental accounts must reflect differences in polluting technology in different locations. Moreover, accounting for differences in polluting technology is even more crucial in light of current policy interest in tracing the actual resource use and pollution generation in any one region or country's imports to measure the global impact, or ecological footprint, of economic activity.
\end{abstract}

Key words: environmental accounting, region-specific data, polluting technology, ecological footprints.

\footnotetext{
${ }^{1}$ The research reported here was part of a PhD study sponsored by the Policy and Resources Committee of the States of Jersey. I would like to thank staff at the States of Jersey and all the Jersey firms and residents who contributed information that went into the construction of the IO table and environmental accounts used here. I am particularly grateful to Dr David Coley, Centre for Energy and the Environment, Exeter University for his input and advice on estimating pollution generation in Jersey, and my PhD supervisors, Kim Swales and Peter McGregor, at the University of Strathclyde for their ongoing input and advice. I am also indebted to Michael Romeril, (formerly) Environmental Adviser to the States of Jersey, Rocky Harris at ONS, Lynn Graham and Antje Branding at the Scottish Executive, and Nick Hanley, University of Stirling, for comments and advice regarding this and related environmental work. I am also grateful for comments on earlier versions of this paper from participants at a meeting of the ESRC Urban and Regional Study Group, Strathclyde Business School, Glasgow, UK in January 2002 and from the anonymous referees who commented on my initial submission of this paper to Regional Studies.
} 


\section{Introduction and background}

A significant degree of responsibility for setting and achieving UK sustainability objectives has been devolved to the Scottish Parliament and the National Assembly for Wales and delegated to the English Regional Development Agencies (RDAs) (Department of the Environment, 1996). Thus, given that the success of national sustainability programmes depends on policies delivered at the regional level, the region has become the natural spatial focus for the evaluation of policies directed at sustainability and formulated within the UK. This means that regional policymakers in the UK need to develop an appropriate database and framework for analysis.

One active debate amongst the English RDAs, Welsh Assembly and the UK Environment Agency, and within the Scottish Executive (in the form of the Scottish Environmental Accounts Working Group) has been the extent to which region-specific environmental and economic data are required to perform this task. Generally, in the absence of existing regional data, and given the costs and survey problems involved in region-specific data collection and reporting, the possibility of adjusting more readily available national data is seen as a tempting option. But what is the likely size of the loss in information if such an option is pursued? Allsopp (2003) identifies the costs involved in data collection at the regional level in terms of diseconomies of scale and sampling issues. However, he fails to consider the potential benefits where tailored regional data collection would allow identification of differences in production technology and consumption behaviour relative to national average and attention to local preferences in terms of the value associated with environmental quality.

For example, one issue is multi-sectoral accounting modelling at the regional level. There have been a number of developments in terms of how national coefficients can be adjusted to reflect the difference in level and composition of activity in the regional economy. Isserman (1980), Round (1983), Richardson (1985), Flegg et al (1995) and McCann and Dewhurst (1998) provide reviews of how input-output technical coefficients have been adjusted to apply at the regional level. The most common approach appears to be some variant on the use of location quotients (LQs), which basically reflect differences in such factors as the level of employment, the export base, import requirements and/or specialisation at the regional and national levels. However, a crucial point is that developments of the methodology for adjusting national input-output coefficients have tended to focus on differences in trade rather than differences in technology. As we will see in this paper, there is a link to environmental relationships given the strong link 
between specific industrial outputs and pollution/resource use levels. While there is no disputing the importance of differences in import requirements at the national and regional levels, and the extent of inter-regional, as opposed to inter-national trade, there is a strong a priori case that when it comes to economy-environment relationships, differences in technology are likely to dominate. For example, Scotland has a greater existing capacity for electricity generation from renewable sources technology in Scotland, with the share of Scottish electricity production from renewable sources already meeting the target of $10 \%$ by 2010 set for the UK as a whole (DTI, 2003).

The argument motivating this paper is that if national coefficients for economy-environment relationships are applied to regions without any adjustment for differences in polluting consumption behaviour and production technology there is likely to be a significant information loss. Moreover, it precludes the potential to tailor data collection and reporting to reflect local preferences in terms of environmental quality.

In order to assess the nature of the information loss, I take the example of Jersey, a crown dependency of the UK located in the Channel Islands. Whilst the Jersey economy is atypical in a number of respects, there are high quality economy-environment data for Jersey, allowing a robust comparison between results using region-specific technical coefficients and UK-adjusted national coefficients. ${ }^{2}$

The remainder of the paper is structured as follows. Section 2 provides a brief overview of the general method used to report sectoral environmental accounts in this study. In Section 3 I consider the current state of economic-environmental accounting at the national and regional levels in the UK. In Section 4 I outline three alternative approaches to estimating regional emissions accounts. Then, in Section 5, I use Jersey as a case study to compare the results of the two extreme cases: fully region specific data against the use of adjusted national coefficients. In Section $6 \mathrm{I}$ assess the added precision from estimating and using region-specific environmental data for Jersey and in Section 7 I consider the factors that are likely to explain the variation in results using region-specific and adjusted national data. Section 8 briefly considers the issue of

\footnotetext{
${ }^{2}$ Note also that Jersey is not in fact a region of the United Kingdom (or any other larger nation). It is an independent self-governing state. However, the Jersey economy is very closely integrated with that of the UK, sharing its language, currency, exchange and interest rates. Moreover, the majority of Jersey's trade flows are with the UK. Therefore, in the absence of Jersey-specific data, the UK would seem to be the natural choice of a proxy national economy from which to draw estimates of parameter values (where appropriate UK data exist).
} 
pollution embodied in trade flows, and how the results presented here may inform that debate. Finally, in Section 9 I offer summary and conclusions.

\section{Construction of a consistent set of economic-environmental accounts for a small regional economy}

\subsection{The NAMEA approach to economic-environmental accounting}

A key issue in economic-environmental accounting is that it is not sufficient to establish regular reporting of both economic and environmental data. If there is a need to determine and monitor the impact of the economy on the environment it is necessary to ensure that economic and environmental data are gathered and reported in a consistent format. For this reason the statistical office of the European Union (Eurostat) has launched a project to promote the construction of what are referred to as NAMEA accounts in all EU member states (see Keuning and Steenge, 1999). ${ }^{3}$ A NAMEA database (see Keuning et al, 2001, and Haan, 2001) provides an integrated set of economic and environmental accounts. The economic accounts are the national accounts in input-output (IO) or social accounting matrix (SAM) format and are presented in monetary units. The environmental accounts are reported in physical units and present information on material inputs of natural resources (particularly energy resources) used in each activity and outputs of residuals (pollution and waste materials) generated by activity at a level of sectoral detail consistent with the economic accounts.

More formally, the NAMEA approach involves reporting the total physical amount of emissions, $P_{i k}$, identified by each type of pollutant, $k$, directly generated by each production sector, $i$, over a period identical to the economic. Where emissions are directly generated in final consumption, this becomes $P_{z k}$ for each type of final consumption $z$. For energy/fuel use (or any type of natural resource use), the NAMEA account reports the total physical amounts of energy/fuel used, $F_{i j}$ and $F_{z j}$, for each energy/fuel type $j$ used by each production sector $i$ and final consumption type $\mathrm{z}$ during the accounting period.

\subsection{Estimating emissions generated by economic activity}

\footnotetext{
${ }^{3}$ NAMEA is an acronym for 'National Accounting Matrix including Environmental Accounts'.
} 
The economic-environmental accounts should give the total emissions from each individual sector or final demand category, if this is directly polluting (e.g. the electricity industry burning oil or private households running cars on petrol or diesel). ${ }^{4}$ However, in practice, the flows of pollutants from any one activity over a given time period (usually one year) cannot generally be directly observed. This implies a need to make certain assumptions regarding the relationship between economic activity and pollution generation. The key aspect in determining the flow of emissions that accompanies economic activity will generally be the amount of different types of fuel used and the technology used to combust them, although non-fuel use sources also need to be identified.

The standard assumption is that emissions from any one economic activity are a function of the volume of fuel combusted during that activity plus the levels of output/activity from other polluting processes (see, for example, Beauséjour et al, 1994, Vaze, 1997). Thus, for each production sector, $i$, emissions of each pollutant, $k$, are determined as

$$
P_{i k}=\sum_{j t}\left(e_{i j t}^{k} F_{i j t}\right)+n_{i}^{k} X_{i} \quad \forall i=1, . ., I ; k=1, . ., K ; j=1, . ., J ; t=1, . ., T
$$

where

- $e_{i j t}^{k}$ is an emissions factor, identifying the amount of pollutant $k$ that is generated when sector $i$ uses (combusts) one unit of fuel $j$ using technology/process $t$

- $\quad F_{i j t}$ is the physical quantity of fuel $j$ used by sector $i$ with technology $t$ during the accounting period

- $n_{i}^{k}$ is an output-pollution coefficient quantifying the non-fuel-combustion-related generation of pollutant $k$ per unit of output in sector $i$

- $\quad X_{i}$ is the value of total output produced by sector $i$ in the accounting period

Emissions are determined in the same way for each type of final demand, $\mathrm{z}$ :

$$
P_{z k}=\sum_{j t}\left(e_{z j t}^{k} F_{z j t}\right)+n_{z}^{k} C_{z} \quad \forall z=1, . ., Z ; k=1, . ., K ; j=1, . ., J ; t=1, . ., T
$$


where $C_{z}$ is total expenditure by final demand type $z$ during the accounting period.

The economic IO (or SAM) accounts provide the monetary data on the elements $X_{i}$ and $C_{z}$ - i.e. levels of economic activity in each production and final consumption sector. ${ }^{5}$ They also provide some information on fuel/energy use, in as much as the sales of energy supply sectors to all production and final consumption sectors are shown in industry-by-industry tables and purchases of energy commodities are given in commodity-by-industry use tables. However, it is important to note that the elements $F_{i j t}$ and $F_{z j t}$ should be reported in physical units (unless the emissions factors $e_{i j t}^{k}$ and $e_{z j t}^{k}$ can be reported in terms of emissions per unit of fuel use in value terms) and should relate to total fuel use (including imported fuels). Generally, what useful information can be obtained from economic accounts depends on the nature of the specific IO tables or social accounting matrices that are available for the economy in question.

\section{Current approaches to economic-environmental accounting at the regional level in the UK}

\subsection{National NAMEA accounts for the UK}

The UK has already adopted the Eurostat guidelines in reporting 76-sector economicenvironmental accounts in the NAMEA format at the national level (see Vaze, 1999). ${ }^{6}$ The economic IO accounts take the form of an industry-by-commodity use matrix. The environmental component reports pollutants generated and different types of fuels used by 76 production sectors and one type of final consumption, aggregate households. ${ }^{7}$ This gives us UK national estimates of $P_{i k}^{U K}, P_{z k}^{U K}, F_{i j}^{U K}$ and $F_{z j}^{U K}$. While staff at the Environmental Accounts Branch of National Statistics confirm that in principle the UK method of estimating sectoral emissions is consistent with equations (1) and (2) above, they acknowledge that in practice a number of adjustments are

\footnotetext{
${ }^{4}$ Indirect pollution generation embodied in final consumption can also be accounted for in an economic-environmental IO or SAM framework. I return to this issue below in Section 8.

${ }^{5}$ It may be preferable to relate non-fuel-related emissions to some variable other than total activity, as defined by the value of output or total expenditure, where more appropriate data are available.

${ }^{6}$ The UK NAMEA accounts can be downloaded at http://www.nationalstatistics.gov.uk/CCI/nscl.asp? $\mathrm{ID}=6805$.

${ }^{7}$ The 76-sector NAMEA breakdown of activities maps to the 128-sector classification of the UK IO accounts, with some IO sectors aggregated and some disaggregated in the NAMEA to focus on key polluting sectors and/or energy users.
} 
made. However these are not specified and a full account of the method used to estimate the sectoral emissions levels reported in the UK NAMEA accounts is not supplied. In particular, while the UK NAMEA accounts do report the total amount of each type of fuel used by each production sector and final demand category, these are not disaggregated by combustion technology to give the $F_{i j t}^{U K}$ and $F_{z j t}^{U K}$ required for estimating (1) and (2). Moreover, no information is given on the emissions factors, $e_{i j t}^{k, U K}, e_{z j t}^{k, U K}, n_{i}^{k, U K}$ and $n_{z}^{k, U K}$.

\subsection{Economic and environmental accounting at the regional level in the UK}

While National Statistics does produce annual regional economic accounts for the UK, these are not in the form of IO tables, and there has been no attempt by this body to extend the NAMEA programme at the regional level in the UK. As noted in the introduction, the English RDAs, the Welsh Assembly and the UK Environment Agency have carried out their own consultation on developing economic-environmental accounts though this is in the absence of region-specific economic IO tables for the English regions. Welsh IO tables are produced by the Welsh Economic Research Unit at Cardiff Business School, but this is independent of, and therefore, not necessary consistent with, the national IO framework used by National Statistics. In the case of Scotland, on the other hand, the Scottish Executive regularly publish Supply and Use and analytical IO tables at the 128-sector breakdown used in UK IO accounting by National Statistics. The Scottish tables are constructed using the same survey data and other underlying data as used in the UK accounts, using a boosted survey sample for Scotland. ${ }^{8}$

In terms of regional environmental data, the only semi-official set of accounts to date is a study by Salway et al (2001) ${ }^{9}$. This study estimates emissions of the three main greenhouse gases $\mathrm{CO}_{2}$, methane $\left(\mathrm{CH}_{4}\right)$ and nitrous oxide $\left(\mathrm{N}_{2} \mathrm{O}\right)$ - for each of the four constituent countries (England, Scotland, Wales and Northern Ireland) for the years 1990, 1995, 1998 and 1999. However, emissions are reported for the $\mathrm{IPCC}^{10}$-classified sources used in the UK national air emissions inventory rather than the Standard Industrial Classification (SIC) of activities used in

\footnotetext{
${ }^{8}$ Despite this, inconsistencies and incompatibilities remain between the Scottish and UK IO accounts (see Ferguson et al, 2004)

${ }^{9}$ The Salway et al (2001) study is not in the public domain. It was carried out by AEA Technology, a commercial body that constructs the UK National Air Emissions Inventory, and was co-funded by Defra, the National Assembly for Wales, the Scottish Executive and the Department of the Environment, Northern Ireland. However, the Scottish Executive kindly made the report available to me for use in another study to construct a partial NAMEA framework for Scotland with $\mathrm{CO}_{2}$ emissions reported at the sectoral level (Turner, 2003).

${ }^{10}$ IPCC stands for Intergovernmental Panel on Climate Change.
} 
UK economic accounting. In Turner (2003) I report on a pilot study instigated by the Scottish Environmental Accounts Working Group (SEAWG) to develop a basic NAMEA framework for Scotland for the single pollutant $\mathrm{CO}_{2}$. I find that there are two main problems with the regional emissions data reported by Salway et al (2001).

The first problem is that it is not clear how region-specific the data are that Salway et al (2001) report for Scotland, Wales, England and Northern Ireland. The second is the difficulty in mapping IPCC activities to the SIC classification of activities. Salway et al (2001) did have access to information on source-or site-specific (point) emissions of $\mathrm{CO}_{2}$ in each region. These are generally large industrial installations, hospitals etc that can be easily reclassified under the SIC system. Moreover, these particular emissions data are region-specific and likely to be accurate. However, Salway et al (2001) do not make clear what share of emissions attributed to each of the four regions fall under this category.

For all domestic, agricultural and non-point commercial/industrial/public sector activity emissions a method called 'area source mapping' is used to allocate emissions to regions. This involves using surrogate datasets, such as population and household fuel use data (for domestic activities), land cover and livestock data (for agricultural activities) and employment data (for industrial/commercial/public sector activities). In the case of emissions from road transport, the third 'road transport mapping' method is employed, making some (unspecified) use of Department of Transport data such as the UK National Transport Survey. However, no details are given on how these mapping techniques are carried out for each of the UK regions.

The first problem, then, is that without fuller information on the mapping methods used, it is difficult to judge the quality and region-specificity of any results using the latter two methods. The second is how to map emissions inventory data to economic sectors. Even if the quality and region-specificity of Salway et al's (2001) emissions estimates for each of the UK regions is judged to be acceptable, there remains the question as to whether these can be reported for a sectoral breakdown that is consistent with the SIC classification in the economic accounts. For example, the IPCC classified activity 'road transportation' is carried out by most economic sectors. That is to say, in the SIC accounting system, commercial road transportation services are distinguished from 'in-house' transportation activities carried out by individual production sectors and final demand categories, whereas in the IPCC system all road transportation activities are classified together. Similarly, the emissions inventory approach reports energy-related emissions 
from the commercia//institutional sector, but again this covers a large range of SIC classified sectors, Even where there is more specific identification of activities, for example 'agriculture/forestry/fishing', this still covers at least 3 SIC classified activities.

The key issue is that Salway et al (2001) appear mainly use a 'top-down' method to allocate UK emissions, reported for IPCC-classified sources, among regions, rather than a 'bottom-up' approach examining region-specific sources of emissions. The benefit of adopting a top-down approach is that it is relatively cheap and gives regional accounts that are numerically consistent with existing national accounts. Allsopp (2003) is correct to identify the trade-off between the costs and benefits of collecting and reporting data at the regional level. However, this trade-off is extremely difficult to express explicitly or precisely if region-specific data are not available in the first instance. In the absence of region-specific data to quantify the benefit side of the trade-off, this assessment can only be made on the basis of a priori beliefs on how similar or different regions and nations actually are. Therefore, I would argue that where there is interest in understanding economy-environment relationships, it is preferable to take an explicitly 'bottomup' approach to develop an understanding of the sources of emissions at the regional level (even if these turn out to be similar to sources at the national level).

Perhaps the crucial issue, given the current trend towards devolution of responsibility for sustainability policy, is that, where decentralisation is intended to exploit local policymakers' knowledge of regional economic conditions and environmental preferences, the acceptability of any loss of local accuracy is likely to decrease. In these circumstances, the concern will be less one of whether regional accounts are numerically consistent with national accounts and more one of whether the regional accounts are appropriate for addressing issues that are considered important at the local level. That is to say, as well as concerns over accuracy, there may be a need to tailor regional data collection and reporting to address local problems. One issue may be that variation in the level of disaggregation of activities identified is desirable at the regional level. For example, in the case of Jersey, where the consumption activities of visitors to the Island are thought to have significant impacts on the local environment, specific attention has been given to developing a tourist survey that elicits information on polluting activities such as fuel use.

\section{Three alternative approaches to estimating a 'bottom-up' regional emissions account}


It is useful to consider three possible categories of emissions estimates within the NAMEA integrated economic-environmental accounting framework that allow us to adopt a more 'bottomup' approach: ${ }^{11}$

\section{A. Fully region-specific}

Estimation of (1) and (2) using region-specific data on fuel uses, $F_{i j t}$ and $F_{z j t}$, fuel and non-fuel related emissions factors, $e_{i j t}^{k}, e_{z j t}^{k}, n_{i}^{k}$ and $n_{z}^{k}$.

\section{B. Partially region-specific}

Estimation of (1) and (2) using region-specific data on fuel uses or emissions factors for all or some of the I production and/or Z final consumption groups. Given the resource costs involved in constructing a region-specific set of economic-environmental accounts, it may be appropriate to focus on key sectors/activities where pollution/energy intensities are expected to deviate significantly from national average. ${ }^{12}$

\section{Fully national-adjusted}

Where region-specific data are not available on either fuel uses or emissions factors, (1) and (2) cannot be fully estimated. An alternative course of action would be to take estimates of (1) and (2) for the national economy (or a comparable region) and divide these through by total sectoral activity to determine national average emissions intensities for each production sector, $i$, and pollutant, $k$. Taking the UK as our example national economy, for production sectors these are defined as $m_{i k}^{U K}$, where

$$
m_{i k}^{U K}=P_{i k}^{U K} / X_{i}^{U K} \quad \forall i=1, . ., I, k=1, . ., K
$$

and for final consumption, direct emissions coefficients are defined as

\footnotetext{
${ }^{11}$ The following assumes that region-specific data on sectoral activity levels, $X_{i}$, and final demands, $C_{z}$, or other appropriate economic data, are available in all cases. However, it is commonly the case in the UK that the regional economic data required under the NAMEA approach - i.e. in the form of region-specific IO tables - will not be available on sectoral activity levels.

${ }^{12}$ For example, in a recent study where we construct an inter-regional environmental IO and SAM framework for Scotland and the rest of the UK, we focus on incorporating region-specific data for the Scottish electricity sector (see McGregor et al, 2004c).
} 


$$
m_{z k}^{U K}=P_{z k}^{U K} / C_{z}^{U K} \quad \forall z=1, . ., Z, k=1, . ., K
$$

We can then make adjusted-national estimates of sectoral emissions by rearranging (3) and (4) and substituting in region-specific data on $X_{i}$ and $C_{z}$ to estimate total emissions generated in each production and final consumption sector. ${ }^{13}$ For example

$$
P_{i k}^{R}=m_{i k}^{U K} X_{i}^{R}=\left[\frac{P_{i k}^{U K}}{X_{i}^{U K}}\right] X_{i}^{R}
$$

where superscript $\mathrm{R}$ denotes the region to which the estimate applies. This would assume that the regional industry has the same fuel use and technology as the nation in generating emissions of pollutant $k$ in sector $i$.

\section{Jersey as a case study}

Using Jersey as an example it is possible to make a useful comparison of the alternative methods of estimating regional economic-environmental accounts. This is because Jersey has invested resources in constructing a set of region-specific economic-environmental accounts in which confidence levels are high with respect to accuracy. These accounts are, of course, of interest in themselves. However, their existence also permits a comparison of the results of estimating economic-environmental accounts using the two extremes in the methods identified above - i.e. method A, fully region-specific estimates of equations (1) and (2), and method C, estimates based on adjusted-national emissions intensities (where the UK is taken as the most appropriate national proxy to estimate unknown Jersey parameters).

\subsection{Policy background}

The States of Jersey have made sustainable development a key policy objective. As an independent, self-governing state Jersey has full responsibility for achieving the commitment to sustainable development stated in the States of Jersey's annual policy report in 1995 (States of Jersey, 1995), and the environmental objectives stated in the States' Environmental Charter, 
endorsed in 1996 (States of Jersey, 1998). However, Jersey is also a voluntary party to UK international environmental commitments, such as the Kyoto Protocol. Given this emphasis on sustainability policy, the States of Jersey has recognised that credible decision making on environmental issues requires an appropriate database and empirical framework for analysis. In this context, Jersey's requirements mirror those of the devolved administrations in the UK.

Jersey initiated the project upon which this paper is based in an attempt to construct a set of economic-environmental accounts in the form suggested by the Eurostat NAMEA programme. This involves augmenting the existing $(25 \times 25)$ industry-by-industry economic input-output (IO) accounts for 1998 with information on the physical use of different types of energy and the direct pollution generation for each of the 25 production and 12 final demand sectors identified in the IO tables. ${ }^{14}$

Because the States of Jersey had stated an interest in both economic and environmental issues from the outset, it was possible from the start to gear the accounting process towards construction of a NAMEA framework. Specifically, particular attention was paid to developing a database that would allow identification of economic activities that are likely to be important in terms of environmental questions. Efforts were also made to ensure that adequate and appropriate data were collected to develop a consistent set of environmental accounts for the same sectoral breakdown as in the economic accounts.

\subsection{Region-specific estimates of emissions generation for Jersey}

The first element of a basic NAMEA account is resource use. Here I focus on energy-use, as this is the key source of pollution generation in Jersey. In the Jersey IO accounts all energy commodities are imported by the two energy supply/distribution sectors, 'Electricity' and 'Gas, Oil \& Fuel Distribution'. Sales of these commodities for use as inputs to production/final consumption in different sectors of the economy are recorded in monetary units (£million) along the 'Electricity' and 'Gas, Oil \& Fuel Distribution' rows of the IO table. However, corresponding data were also collected on the physical use of the eight fuel types supplied by 'Gas, Oil \& Fuel Distribution' for use by each production sector and final demand category identified in the IO

\footnotetext{
${ }^{13}$ Here I state emissions intensities in terms of gross sectoral output and total final consumption expenditure. However, emissions intensities could be stated in terms of other variables that can be measured for both economies (although this would not strictly be consistent with standard NAMEA accounting conventions).

${ }^{14}$ Construction of the 1998 economic and environmental accounts for Jersey is described in detail in Turner (2002).
} 
accounts. Table 1 identifies the nine different energy types and the type of activity they are used for in Jersey.

\section{Insert Table 1 around here}

The second element of the environmental accounts is the physical amount of pollution generated by economic activity in Jersey in 1998. As explained above, this is determined by estimating (1) and (2) for each production sector and final demand category respectively. The Jersey economy has a very small manufacturing sector, with none of the heavy industries where production processes themselves are often pollution intensive (independent of energy use). We would therefore expect emissions from fuel/energy use to be the main source of pollution in Jersey. In other words, we would expect the elements $n_{i}^{k}$ and $n_{z}^{k}$ for Jersey in equation (1) and (2) to be equal to zero across most production sectors and final demand categories respectively, meaning that emissions will depend primarily on the type and amount of fuel used and on combustion technology.

For example, emissions from heating-oil-use are a function of both the type of heating oil (kerosene, light fuel oil or gas oil) and on the combustion technology (heating system) used. Emissions are also produced when gas oil is used (along with heavy fuel oil) in the production of electricity, which involves yet another different type of combustion technology. In terms of motive fuel use, emissions are a function of both the type of vehicle used (combustion technology) and what type of fuel the vehicle runs on. Jersey emissions factors, that is the $e_{i j t}^{k}$ and $e_{z j t}^{k}$ in equations (1) and (2), for the motive and non-motive fuel types and technologies were identified in an earlier study (Coley, 1994, which adapts IPCC and Warren Springs Laboratory (WSL) emissions factors to reflect polluting technology in Jersey). The Jersey emissions factors are discussed and reported in detail in Turner (2002).

There is another type of motive fuel use in Jersey: aviation fuel is used to operate private and commercial aircraft ${ }^{15}$. Data were available on the total amounts of aviation gas and jet fuel

\footnotetext{
15 Another type of motive fuel combustion that is not covered in the present study, but which leads to emissions generation, is shipping activities. Coley (1994) did not make any attempt to identify fuel used in shipping activities due to problems of data availability. A previous study of energy supply and use in Jersey (Burek, 1988) had found that shipping represents a relatively small proportion of fuel use in the economy. Moreover, as with the case of air transport, there are problems in determining how much of the fuel supplied to marine users can actually be classified as being
} 
imported and supplied in 1998. However, the amount of aircraft fuel supplied in any one economy is unlikely to correspond to the amount of fuel combusted within that economy's borders. Therefore I adopt the WSL concept of 'aircraft movements', which is consistent with Coley (1994). An aircraft movement is one landing/takeoff cycle of up to 1000 metres and emissions factors are stated in terms of each movement rather than the amount of fuel consumed. Therefore, in estimating emissions from aviation fuel use, the number of aircraft movements (take-off and landing cycles at Jersey airport) in 1998 is taken as a proxy for the $F_{i j t}$ and the emissions factors, $e_{i j t}^{k}$ are given for the WSL estimates for a 'small airport' (see Turner, 2002). All direct emissions generation from aircraft movements is allocated to the 'Sea \& Air Transport and Transport Support' sector. ${ }^{16}$

\section{Insert Table 2 around here}

There are several sources of pollution, summarised in Table 2, in Jersey that are not related to the combustion of fuels. Such emissions are calculated by including the additional non-fuel combustion related element, $n_{i}^{k} X_{i}$ and $n_{z}^{k} C_{z}$, in the estimation of equations (1) and (2) for the relevant production sectors and final demand groups. The emissions factors, $n_{i}^{k}$ and $n_{z}^{k}$, were identified by the Coley (1994) study.

Adding non-fuel combustion related emissions to total emissions from fuel use for each production sector, $i$, and final demand category, $z$, gives us total emissions of each pollutant by each sector and final demand category.

For purposes of comparison with the UK-adjusted coefficients in the next section, the NAMEA data on emissions-by-sector can then be used to derive a set of direct average emissions intensity coefficients relating the generation of emissions to total activity in each production and final demand category. Denoting Jersey by the superscript $\vartheta$, these are defined for the $\mathrm{I}=25$ production sectors as

combusted within the economy's borders. However, when appropriate data do become available, emissions from shipping and marine fuel use should be separately identified and accounted for in Jersey.

16 This allocation may not be entirely satisfactory: Jersey Aero Club (part of the 'Total Recreation, Culture \& Sport' (TRCS) sector) and private flyers (both local and non-local) also purchase aviation gas and fly in and out of Jersey Airport. Therefore some aircraft movements should really be allocated to TRCS, Jersey households and tourists. However, no information is available on how many aircraft movements these groups account for, and, due to the 


$$
m_{i k}^{\vartheta}=P_{i k}^{\vartheta} / X_{i}^{\vartheta} \forall i=1, . ., I ; k=1, . ., K
$$

and for final consumption, the direct emissions coefficients are defined as

$$
m_{z k}^{\vartheta}=P_{z k}^{\vartheta} / C_{z}^{\vartheta} \quad \forall z=1, . ., Z ; k=1, . ., K
$$

(6) and (7) are analogous to the UK coefficients stated in (3) and (4) above. This gives us is the $(\mathrm{KxI}=8 \mathrm{x} 25)$ Jersey-specific matrix $M_{i}^{\vartheta}$ of direct emissions intensity coefficients for the 25 production sectors and the $(\mathrm{KxZ}=8 \mathrm{x} 12)$ Jersey-specific matrix $M_{z}^{\vartheta}$ of direct emissions intensity coefficients for final consumption activities. These matrices are represented (in transpose form) in Table 3 below. Note that $M_{z}^{\vartheta}$ is effectively an 8 by 6 matrix showing direct emissions of each pollutant by the six final demand categories - five household groups (income quintiles) and tourists - that are responsible for direct emissions generation in Jersey.

\section{Insert Table 3 around here}

\subsection{UK-adjusted estimates of emissions generation for Jersey}

Using equations (3) and (4) and the 1998 UK NAMEA dataset and focussing on the $\mathrm{K}=7$ pollutants that are common to both the UK and Jersey accounts, we identify a (KxI=7x76) UK matrix $M_{i}^{U K}$ and a $(\mathrm{KxZ}=7 \mathrm{x} 1)$ vector $m_{z}^{U K}$ of direct emissions intensities. Note that $\mathrm{Z}=1$ because aggregate household demand is the only type of final consumption for which direct emissions generation is reported in the UK NAMEA accounts.

The matrix $M_{i}^{U K}$ must be aggregated to make it consistent with the sectoral breakdown of the Jersey accounting system. This involves the following steps:

1. A weight of zero is attached to the column vector of output-pollution coefficients for all sectors that are present in the UK economy but not in the Jersey economy.

problem discussed above, it is not possible to make an allocation based on shares in fuel purchases. This is a problem that should be rectified if and when better data become available 
2. The remaining sectors that are present in both economies are aggregated to the sectoral breakdown identified in the Jersey IO tables ${ }^{17}$

3. For each Jersey NAMEA sector, the column vectors from matrix $M_{i}^{U K}$ are then weighted according to the contribution of each component activity to the total output of the Jersey sector.

This allows the derivation of a KxI (7x25) matrix, $M_{i}^{U K(\vartheta)}$ of UK-adjusted direct emissions coefficients for Jersey production sectors (for 1998). This matrix is shown (in transpose form) in Table 4.

\section{Insert Table 4 around here}

Applying the UK-adjusted emissions coefficients in $M_{i}^{U K(\vartheta)}$ and $m_{z}^{U K}$, which I relabel $m_{H H}^{U K}$ ( $\mathrm{Z}=1=$ households), to Jersey means making the assumptions that the fuel intensity of production and consumption does not vary between the UK and Jersey economies and that polluting technology does not vary between the UK and Jersey economies

\section{The added precision from estimating and using region-specific environmental data for Jersey}

The composition of the 25 production sectors is equivalent across both the region-specific coefficients in Table 3 and the UK-adjusted emissions intensity coefficients in Table 4. Therefore, these can be directly compared for the pollutants that are common to both sets. Two crucial observations can be made:

1. The Jersey-specific and UK-adjusted emissions coefficients for any one sector differ significantly in terms of the absolute pollution intensities of production/consumption (i.e. the level of emissions per unit of output/expenditure).

\footnotetext{
${ }^{17}$ Details on the composition of each of the production sectors identified here (according to 1992 SIC classification) are available on request from the author at karen.turner@strath.ac.uk.
} 
2. Overall, the sets of Jersey-specific and UK-adjusted coefficients differ significantly in terms of the relative pollution intensities of the different activities in the Jersey economy.

Both of these factors are important. If the absolute intensities are over- or under-stated, this will lead to errors in estimating total pollution in the Jersey economy. If the relative intensities are incorrect this will lead to errors in determining the direct (and indirect ${ }^{18}$ ) contributions of different production sectors and consumption activities to the pollution problem. This could lead to errors in terms of prioritising activities in determining policy to reduce pollution. As well as affecting the accuracy of the base-year environmental accounts, both these factors would impact on the accuracy of any economic-environmental model for Jersey based on these data. ${ }^{19}$

We can determine the magnitude of the first problem (the differences in the absolute level of the pollution intensities across all sectors) by looking at the estimates of total generation for each pollutant, $k$, from the two methods. First the Jersey-specific data are used to calculate (1) and (2) for each pollutant, $k$, summed across all production and final consumption activities:

$$
\begin{aligned}
& P_{k}^{\vartheta}=\sum_{i} P_{i k}^{\vartheta}+\sum_{z} P_{z k}^{\vartheta}=\sum_{i j t} e_{i j t}^{k, \vartheta} F_{i j t}^{\vartheta}+n_{i}^{k, \vartheta} X_{i}^{\vartheta}+\sum_{z j t} e_{z j t}^{k, \vartheta} F_{z j t}^{\vartheta}+n_{z}^{k, \vartheta} C_{z}^{\vartheta} \\
& \forall k=1, . ., K ; i=1, . ., I ; z=1, . ., Z ; j=1, . ., J ; t=1, . ., T
\end{aligned}
$$

where the superscript $\vartheta$ indicates the use of Jersey-specific data and Jersey-specific results. The exercise is then repeated using the UK-adjusted coefficients:

$$
\begin{aligned}
& P_{k}^{U K(\vartheta)}=\sum_{i} P_{i k}^{U K(\vartheta)}+\sum_{z} P_{z k}^{U K(\vartheta)}=\sum_{i} m_{i k}^{U K(\vartheta)} X_{i}^{\vartheta}+m_{H H}^{U K} C_{H H}^{\vartheta} \\
& \forall k=1, . ., K ; i=1, . ., I ; z=1(H H)
\end{aligned}
$$

The results for the $\mathrm{K}=7$ pollutants that are common to both the Jersey-specific and UK-adjusted data are shown in the first two columns of Table 5.

\footnotetext{
${ }^{18}$ See the attribution analy ses for pollution generation in Jersey reported in McGregor et al (2004).

${ }^{19}$ In terms of modelling, note that, unlike the UK-adjusted coefficients, the Jersey-specific data do not limit us to the application of fixed IO-ty pe Leontief output-pollution coefficients. Where region-specific, or partially region-specific, data are available to estimate pollution generation using equations (1) and (2) it is possible to model changes in pollution generation due to technology and input substitution effects. However, if we rely on (3) and (4), or (6) and (7), only changes in pollution due to changes in the scale and composition of economic activity can be captured.
} 


\section{Insert Table 5 around here}

Note that there are extremely large differences between the estimates using the two methods. In the case of five out of seven of the pollutants, the UK-adjusted coefficients give estimates that are much larger those found using the Jersey-specific data. The largest difference is in the case of $\mathrm{N}_{2} \mathrm{O}$, with the estimate of total emissions using the UK-adjusted coefficients being more than 153 times the size of the estimate based on the Jersey-specific fuel-use figures and emissions factors. This is an extreme result: the next biggest difference is found in the case of methane, where the UK-adjusted estimate is over $500 \%$ higher than the Jersey-specific one (followed by $35 \%$ for $\mathrm{SO}_{2}$ and $42 \%$ for $\mathrm{NO}_{\mathrm{X}}$ ). In the case of the three remaining pollutants, $\mathrm{CO}_{2}, \mathrm{NMVOC}$ and carbon monoxide (CO), the Jersey-specific estimates of total emissions are higher than the UK-adjusted ones (the UK-adjusted estimates being respectively 26\%, 22\% and 36\% less than the Jerseyspecific ones).

Second, the relative pollution intensities of sectors differ across the two sets of direct emissions intensities shown in Tables 3 and 4. In accounting terms, the main impact of differing relative pollution intensities will be on the contribution of individual production and final demand sectors to total emissions in the base year. Figures 1 and 2 illustrate this point for the individual pollutant $\mathrm{NO}_{\mathrm{X}}$. Figure 1 graphs the Jersey-specific and UK-adjusted $\mathrm{NO}_{\mathrm{X}}$ emissions coefficients for each production sector. Figure 2 shows the (direct) proportionate sectoral contributions to total emissions of $\mathrm{NO}_{\mathrm{X}}$ using the two different methods.

\section{Insert Figures $1 \& 2$ around here}

The direct contribution of each production sector, i, and final demand category, $z$, to total emissions of any one pollutant, $\mathrm{k}$, is determined by the emissions intensity of the activity in question and by the scale of activity. The scale of activity in each production sector, $X_{i}^{\vartheta}$, and

final demand sector, $C_{z}^{\vartheta}$, is common to both calculations. Therefore the differences between the two sets of results shown in Figure 2 are entirely due to the differences in relative pollution intensities (including the zero intensity for all pollutants in the tourist final demand category in the UK-adjusted case). 
For example, according to the UK-adjusted coefficients, 'Land Transport' is the third most $\mathrm{NO}_{\mathrm{X}^{-}}$ intensive production sector in the Jersey economy. However, under the Jersey-specific measures it is only the sixth most $\mathrm{NO}_{\mathrm{X}}$-intensive, with an output- $\mathrm{NO}_{\mathrm{X}}$ coefficient that is much smaller in relative terms. In the Jersey-specific set of pollution coefficients (Table 3) the 'Land Transport' direct $\mathrm{NO}_{\mathrm{X}}$-intensity coefficient is only $2.3 \%$ of the size of the coefficient for the most $\mathrm{NO}_{\mathrm{X}^{-}}$ intensive sector, 'Electricity', while this figure is almost 53\% in the UK-adjusted case. In terms of contribution to total $\mathrm{NO}_{\mathrm{X}}$ emissions, we can see from Figure 2 that 'Land Transport' is attributed with the fourth highest contribution of all the production sectors under the UK-adjusted measure, accounting for $4.53 \%$ of total emissions. However, under the Jersey-specific measure this share is smaller both in absolute and relative terms: with a $0.36 \%$ share of total $\mathrm{NO}_{\mathrm{X}}$ emissions, it has only the eleventh highest contribution of all the production sectors.

Conversely, Figure 1 reveals that 'Public Services' has a higher $\mathrm{NO}_{\mathrm{X}}$-intensity both in absolute and relative terms under the Jersey-specific measure, being the third most $\mathrm{NO}_{\mathrm{X}}$-intensive production sector, compared with fifth under the UK-adjusted measure. Figure 2 shows that if we rely on the UK-adjusted coefficients, 'Public Services' is attributed with only $1.06 \%$ of direct $\mathrm{NO}_{\mathrm{X}}$ generation, the eighth highest contribution of all twenty-five production sectors; however the Jersey-specific measures show its contribution to be much higher, $4.03 \%$, the fourth highest contribution.

\section{Factors underlying the variation in the region-specific and UK-adjusted estimates of economy-environment relationships in Jersey}

Two main factors can be identified that may contribute to the differences in direct emissions intensities shown for equivalent sectors in the Jersey-specific and UK-adjusted sets of coefficients in Tables 3 and 4:

1. Accuracy and tailoring of data collection to region-specific priorities in Jersey.

2. Regional variation in fuel use (types and intensity) and polluting technology in Jersey and the UK.

\subsection{Accuracy and region-specificity of data collection in Jersey}


Due to the size of the Jersey economy, its island status, the structure of the energy supply industry and the availability of earlier studies, such as Coley (1994), it has been possible to construct a highly detailed and accurate database on fuel use and polluting technology. It is unlikely that such a complete database could be constructed for the UK, particularly at the regional level, given the nature of cross border supply and use of fuels. Moreover, the fact that such detailed studies have been carried out for Jersey reflects the high priority that the population and policymakers place on the quality of the environment.

In terms of accuracy, note that the reporting of how the 1998 environmental accounts for Jersey have been constructed, here and in Turner (2002), is characterised by a much greater degree of transparency than the UK NAMEA accounts. For example, as noted in Section 3, the UK reporting does not include any information on what is assumed about polluting technology in order to generate sectoral emissions estimates. The Environmental Accounts Branch of the ONS does acknowledge making adjustments that reflect problems in allocating fuel use and emissions from transport activities. However, these are unspecified. On the other hand, in the Jerseyspecific case it has been possible to clearly identify and state where accounting problems have arisen (see Turner, 2002). This will allow rectification of these problems when and if improved data permit. Conversely, in the case of the UK NAMEA tables it is not possible to identify the nature of any accounting problems, in particular, what impact these would have on any accounting work for Jersey based on UK-adjusted coefficients.

However, the survey issues raised by Allsopp (2003) are important. If it the case that fuel use and polluting technology did not vary greatly between the UK and Jersey, it may be better to use UK data, which is subject to greater economies of scale in collection and more robust sampling techniques. In general, there is likely to be a trade-off between capturing region-specific characteristics and economies of scale in data collection, with the implication that local data may be of worse quality. However, this is not the case in Jersey, where the preference for good quality of environmental data has meant that policymakers have invested significant resources and effort in local data collection of a very high quality.

\subsection{Differences in Fuel Use and Polluting Technology in Jersey and the UK}

The second factor that will contribute to the differences in the UK-adjusted and Jersey-specific estimates is variations in fuel use (types of fuel and amounts used) and polluting technology in 
Jersey and the UK. The Jersey-specific coefficients in Table 3 reflect the actual average emissions intensities (for each pollutant) of each production and final consumption activity that takes place in the Jersey economy. The adjusted national coefficients reflect the average emissions intensities for equivalent activities in the UK, independent of the location of activity.

Thus, by adopting adjusted national emissions coefficients to apply at the regional level involves adopting the two crucial assumptions identified in Section 5 above: that fuel use (type and intensity) and polluting technology at the regional level corresponds to the averages observed for the national economy. If this is not the case, i.e. if one or more of the elements on the right-hand side of equations (1) and (2) differ significantly across space in the national and regional economies, the adjusted national coefficients will mis-represent absolute and relative pollution intensities in the regional economy. This will in turn lead to errors in estimating total pollution generation at the regional level and the contribution of individual activities to this total (even if the assumptions are not violated for all production and final demand sectors), as well as the contribution of the regional economy to total pollution generation at the national level.

The main motivation for investing resources in constructing a set of Jersey-specific economicenvironmental accounts was that important differences are known to exist with respect to the technology used in certain activities in Jersey relative to the UK. For example, all electricity produced in Jersey is generated using oil-powered technology while in the UK a combination of gas-, hydro-, nuclear- and oil-powered techniques is used to generate the total electricity requirement. Waste disposal is another example: in the UK there will be emissions from landfill, while in Jersey all waste is disposed of by incineration or composting. Thirdly, the composition of technologies used for commercial and domestic heating activities in Jersey is known to be different to that found in the UK. With no infrastructure for natural gas to be piped to Jersey it is necessary to import and bottle a combination of propane or butane. As a result, gas-heating systems are expensive relative to other forms of heating and a larger proportion of households and businesses therefore rely on oil-powered heating systems than is the case in the UK.

As explained above, information is not available on the precise mix of polluting technologies used in the UK; in particular the UK NAMEA tables do not include emissions factors for comparison with the ones used for Jersey. However, the UK NAMEA table accounts do include fuel use by sector that allows a direct comparison of the physical fuel use intensities of equivalent activities in the UK and Jersey (but only for some of the fuel types used in Jersey). If fuel-use in 
equivalent sectors differs sufficiently between Jersey and the UK, this alone would cast serious doubt on the validity of using UK-adjusted pollution coefficients to estimate and model pollution generation in the Jersey economy.

First, look at the heating fuel, gas oil ${ }^{20}$. Given what has been explained above about the lack of infrastructure for piping natural gas to Jersey and the consequent reliance on oil-powered heating systems, we would expect to find higher heating oil use intensities in Jersey than in the UK. Figure 3 reveals that this is indeed the case across most production sectors for gas oil use. Note that Figure 3 also reflects another peculiarity of fuel consumption and supply patterns in Jersey: while oil-powered heating systems are generally more prevalent in Jersey than any other type of heating system, gas oil is only used in the commercial sector. Domestic heating systems in Jersey run exclusively on kerosene (and the private household sector is the sole user of kerosene as a heating fuel). Therefore, while the aggregate UK household sector shows a positive, but relatively low, use of gas oil, the Jersey household sector has zero intensity for this fuel. This distinction between different types of fuel (e.g. kerosene or gas oil) used for the same purpose (e.g. running oil-powered domestic heating systems) is crucially important because the pollution properties of different types of fuel can vary significantly. In the current example, the combustion of one kilogram of kerosene using the type of technology identified for heating systems in Jersey generates significantly smaller amounts of $\mathrm{SO}_{2}, \mathrm{NO}_{\mathrm{X}}$ and carbon monoxide than would result from the combustion of one kilogram of gas oil (see Turner, 2002).

\section{Insert Figure 3 around here}

Therefore, if we were to assume that gas oil intensities are the same across equivalent sectors in the UK and Jersey, the result would be significant errors in estimating the amount of gas oil used at both the aggregate and sectoral levels. In terms of total fuel use in the economy, actual total gas oil use in Jersey in 1998 was almost twice as high as would be estimated using the 1998 UKadjusted gas oil intensities. This is consistent with the greater reliance in Jersey on oil-powered heating systems noted above. However, more important in the present context is fuel use at the sectoral level. The fuel-intensities shown in Figure 3 demonstrate that assuming identical gas oil use for equivalent sectors in Jersey and the UK would lead to drastically misleading results, both in terms of the amount of gas oil used and the amount of emissions generated from this type of

\footnotetext{
${ }^{20}$ Gas oil is technically the same fuel as the diesel used for automotive purposes; however it is standard practice to
} define and record supply of gas oil used for automotive purposes separately as 'diesel' (or 'derv'). 
fuel use. This would be the case even if the technology used to combust this type of fuel were identical in the UK and Jersey.

However, it is also the case that automotive fuel use intensities differ across equivalent sectors in Jersey and the UK, even though there are not the same restrictions on combustion technology i.e. there is no restriction on the type of vehicles that can be used on the Island. Figure 4 shows that twenty out of the twenty-five production sectors are significantly less automotive fuel intensive than equivalent sectors in the UK would be. In particular, 'Land Transport' is far less fuel intensive than its UK counterpart, the value of its petrol/derv-output intensity being only $6.2 \%$ of the value of the UK-adjusted intensity. The other five production sectors - 'Quarrying and Construction', 'Total Manufacturing', 'Electricity', 'Gas and Oil \& Fuel Distribution' and 'Telecommunications' - are significantly more automotive fuel intensive than equivalent sectors operating in the UK would be.

\section{Insert Figure 4 around here}

In terms of final demand categories, note again that the UK figures do not separately identify fuel use by tourists, so it is not possible to determine the extent of any variation in automotive fuel use by visitors to Jersey compared to destinations in the UK. However total final consumption by Jersey households is significantly less automotive fuel intensive, despite the high level of private car ownership on the Island (of course this may be expected given the limited road space available to drive on).

So, just as is found in the case of stationary fuel use, it is clearly the case that automotive fuel-use patterns in Jersey are quite distinct from those that underlie the combustion-related element of the UK-adjusted pollution coefficients. Some of the differences in emissions intensities can be related to differences in the types of fuel use associated with their generation. For example, in Turner (2002) I find that the main source of $\mathrm{SO}_{2}$ combustion-related emissions from production activities that take place in the Jersey economy is stationary fuel use (automotive fuel use, other than aircraft movements, does not generate $\mathrm{SO}_{2}$ emissions). Here, I have explained that the main type of fuel involved in stationary combustion in the production sector of the Jersey economy is gas oil. Examination of the output-SO $\mathrm{SO}_{2}$ coefficients in Tables 3 and 4 and the gas oil intensities in Figure 3 show that it is the case that the Jersey-specific output- $\mathrm{SO}_{2}$ coefficients do tend to be higher (lower) than the UK-adjusted ones where gas oil intensities are higher (lower). 
However, in general, the observed differences in the Jersey-specific and UK-adjusted pollution coefficients, and in the estimates of total emissions in Table 5, cannot be explained simply by looking at the differences in fuel intensities. As noted above, no information is available about the emissions factors used to estimate the sectoral pollution levels reported in the UK trial NAMEA accounts. Without this it is difficult to determine whether violation of one or both of the assumptions required for adoption of the UK-adjusted coefficients alone can explain all the observed variation in results. It may be the case that the other potential explanatory factor suggested above, accuracy of data collection, is also important. Nonetheless, the crucial point is that, independent of all other possible explanatory factors, the observed differences in fuel intensities across the board in Jersey (1998) from what would be expected in their UK counterparts are sufficient to render use of pollution coefficients based on UK technical relationships inappropriate.

Again, it would be incorrect to generalise the results reported here to other regional economies. Jersey is a very small and quite idiosyncratic economy. However, what the results here show is that if it is expected that fuel intensities and/or combustion technology are likely to deviate from the national average - for example in domestic fuel use or electricity generation across space in the UK - the case for even partially region-specific data collection should be explored (method B in Section 4).

\section{The pollution content of trade flows}

One factor that I have not attempted to address in the study reported here is any pollution embodied in trade flows. My focus is on accounting for pollution generated within the local economy. The issue of trade has only risen with regard to imported fuels, which are then combusted within the local economy. However, the problem of pollution embodied in trade flows is the source of a significant level of political and academic debate. One of the main contributions has been the concept of ecological footprints (see Wackernagel and Rees, 1996, 1997, Van den Bergh and Verbruggen, 1999). More generally, the concern in this debate is that (final) consumption is the ultimate driving force behind resource use and pollution generation. Of central importance is the recognition that a significant proportion of the resource use and pollution generation indirectly embodied in final consumption in any one region will occur outwith the boundaries of that region. 
I explore this issue in more depth elsewhere in several co-authored papers that focus on adapting IO and SAM accounting techniques to address the problem of resource use and pollution embodied in final consumption in Jersey (see McGregor et al, 2004) and Scotland and the rest of the UK (see Ferguson et al, 2004, McGregor et al, 2004a,b,c). Here, I draw attention to the implications of the results reported here to this debate.

There are huge information problems in tracing through the actual resource use and pollution generation in any one region or country's imports. To do this accurately implies the need for a set of inter-regional world IO tables (see McGregor et al, 2004). In practice short-cut methods are generally employed, often involving the assumption that the resource and/or polluting characteristics of economies from which imports are drawn are identical to those for the local economy (e.g. Bicknell et al, 1998). Of particular relevance to my findings here, the UK National Statistics agency recently carried out a study (National Statistics, 2002) examining alternative approaches to accounting for pollution embodied in imports to UK consumption. One option they consider is applying UK emissions intensities to goods and services imported from other countries. This is an approach that is commonly adopted in computing ecological footprints and has been applied to several recent ecological footprint calculations for UK regions (e.g. Best Foot Forward Ltd, 2004).

However, the results I have reported here suggest that this may lead to extremely misleading results. The application of UK average emissions intensities implies that Jersey is like the UK. While this is true, in terms of sharing broad similarities such as culture and climate, we have seen here that the use of UK pollution coefficients leads to very inaccurate results. This, then, raises the question of the impact of assuming that UK technology applies more widely, to regions and nations that are even less similar to the UK.

\section{Summary and conclusions}

In this paper I have identified three alternative approaches to estimating a sectoral emissions account at the regional level: using fully region-specific data, partially region-specific data and adjusted national data. Jersey is used as a case study to assess the added precision gained by using region-specific data compared to the other extreme of using entirely adjusted national data. This is possible because of the availability of very detailed regional data, in which there is a high 
degree of confidence in terms of accuracy. I find that the degree of information loss, both in terms of the absolute value of sectoral and total emissions estimates, and in terms of the relative contribution of different activities, when adjusted national data are used is so large as to render this data generated by this approach of no use whatsoever in the case of Jersey.

The Jersey case study should of interest in its own right, particularly to those interested in economy-environment relationships in this type of small open island economy. However, the findings are of more general interest. First, this is an example of using fully region-specific data to construct an economic-environmental account. While adopting this approach permits focus on issues that are of particular interest at the regional level the resource costs of investing in such a database are significant, and will be higher the larger the economy, and the more complex transactions and trade flows become. However, my argument is that these costs should be considered against the benefits of using region-specific data where technical relationships in polluting activities are expected to deviate significantly from the national average. I highlight the fact that Jersey is a particularly small and idiosyncratic economy: for other UK regions that are not quite so atypical, a partially region-specific approach that focuses on key areas where polluting technology is expected to deviate significantly from the UK average may be more appropriate.

However, if we consider the findings reported here in a wider context, I argue that the focus on differences in polluting technologies in different regions has important implications for the debate on how to measure the environmental impact of consumption in any one economy. Due to the information problems in tracing through the actual resource use and pollution generation embodied in any one region or country's imports, a short-cut method of assuming that the resource and/or polluting characteristics of economies from which imports are drawn are identical to the local economy is commonly adopted. However, the findings reported here suggest that making this type of assumption is likely to give very misleading results.

More generally, the finding that the key difference between Jersey and the UK is in terms of technology rather than trade has implications for specific applications such as multi-sectoral modelling of economy-environment interactions at the regional level. It is commonly the case that, as in the generation of regional IO tables using national data, nationally estimated parameters are taken to apply at the regional level. Again, the findings reported here suggest that this type of assumption is likely to give very misleading results. 
All of this brings us back to the ongoing debate in the UK regarding the extent to which regionspecific environmental and economic data are required to carry out devolved sustainability policy analysis. Allsopp (2003) highlights the trade-off between the desire for region-specific data and the costs and sampling issues involved in collecting and reporting good quality data. However, so far, a key issue appears to have been neglected in this debate: what are the implications if the regions actually are different from the national economy? This paper has argued that the benefits of region-specific data cannot be properly assessed in the absence of some degree of regionspecific data collection in the first place. 


\section{References}

Allsopp, C. (2003) 'Review of statistics for economic policymaking: first report to the Chancellor of the Exchequer, the Governor of the Bank of England and the National Statistician', Her Majesty's Stationary Office (HMSO), London.

Beauséjour, L., Lenjosek, G. and Smart, M. (1994) 'An environmental CGE model of Canada and the United States', Working Paper No. 92-04, Department of Finance Canada.

Best Foot Forward Ltd. (2004) 'Scotland's Footprint: a resource flow and ecological footprint analysis of Scotland', Best Foot Forward, Ltd., Oxford.

Bicknell, K.B., Ball, R.J., Cullen, R. and Bigsby, H.R. (1998) 'New methodology for the ecological footprint with an application to the New Zealand economy', Ecological Economics, Vol.27, pp149-160.

Burek, S. (1998) 'Jersey Energy Supply 1988'. Report commissioned by the States of Jersey from the Centre for Energy and the Environment, Exeter University.

Coley, D. (1994) 'The estimation of greenhouse gas emissions from Jersey'. Report commissioned by the States of Jersey from the Centre for Energy and the Environment, Exeter University, in Spring 1994.

Department of Environment (1996) 'Indicators of Sustainable Development for the United Kingdom', HMSO, London.

Department of Trade and Industry (2003) 'Energy White Paper: Our Energy Future-Creating a Low Carbon Economy', the Stationary Office, London.

Ferguson, L., P.G. McGregor, J.K. Swales and K. Turner, (2004) 'The environmental "trade balance" between Scotland and the Rest of the UK', policy paper published by the Scottish Economic Policy Network, 2004, available from author on request or via www.scotecon.net. 
Flegg, A.T., Webber, C.D. and Elliot, M.V. (1995) 'On the appropriate use of location quotients in generating regional input-output tables', Regional Studies, Vol.29, No.6, pp547-561.

Haan, M (2001) 'A structural decomposition analysis of pollution in the Netherlands', Economic Systems Research, Vol.13, No.2, pp.181-196.

Harrigan, F.J., McGilvray, J.W. and McNicoll, I.H. (1980a) 'Simulating the structure of a regional economy', Environment and Planning A, Vol.12, No.8, ppp927-936.

Harrigan, F.J., McGilvray, J.W. and McNicoll, I.H. (1980b) 'A comparison of regional and national technical structures', Economic Journal, Vol.90, No.360, pp795-810.

Isserman, A.M. 'Estimating export activity in a regional economy: a theoretical and empirical analysis of alternative methods', International Regional Science Review, Vol.5, No.2, pp155184.

Keuning, S.J. and Steenge, A.E. (1999) 'Introduction to the special issue on "Environmental extensions of national accounts: the NAMEA framework', Structural Change and Economic Dynamics, Vol.10, pp1-13.

Keuning, S.J., Dalen, J.v. and Haan, M.d. (1999) 'The Netherlands' NAMEA: presentation, usage and future extensions', Structural Change and Economic Dynamics, Vol.10, pp15-37.

Learmonth, D., McGregor, P.G., Swales, J.K., Turner, K.R. and Yin, Y.P. (2002) 'The importance of the regional/local dimension of sustainable development: an illustrative computable general equilibrium analysis of the Jersey Economy', mimeo, Strathclyde Papers in Economics, No.02-04.

Leontief, W. (1970) 'Environmental repercussions and the economic structure: an input-output approach', Review of Economic Statistics, Vol.52, pp.262-277.

Leontief, W. and Ford, D. (1972) 'Air pollution and the economic structure: empirical results of input-output computations', in Input-Output Techniques, edited by Brody, A. and Carter, A.P. 
McCann, P. and Dewhurst, J.H.Ll. (1998) 'Regional size, industrial location and input-output expenditure coefficients', Regional Studies, Vol.32, No.5, pp435-444.

McGregor, P.G., Swales, J.K. and Turner, K.R. (2004) 'An input-output based alternative to "Ecological Footprints" for tracking pollution generation in a small open economy', mimeo, Strathclyde Discussion Papers in Economics, No. 04-04.

http://www.economics.strath.ac.uk/Research/Discussion_papers/discussion_papers.html

McGregor, P.G., McLellan, D., Turner, K.R. and Swales, J.K. (2004a) 'Attribution of pollution generation to local private and public demands in a small open economy: results from a SAMbased neo-classical linear attribution system for Scotland', mimeo, Strathclyde Discussion Papers in Economics, No.04-08.

http://www.economics.strath.ac.uk/Research/Discussion_papers/discussion_papers.html

McGregor, P.G., Swales, J.K. and Turner, K.R. (2004b) 'The impact of Scottish consumption on the local environment: an alternative to the ecological footprint?' Quarterly Economic Commentary (Fraser of Allander Institute, University of Strathclyde) Vol.29, No.1.

McGregor, P.G., Swales, J.K. and Turner, K. (2004c) 'The environmental 'trade balance' between Scotland and the rest of the UK: an inter-regional input-output and SAM analysis', mimeo, Strathclyde Discussion Papers in Economics, 04-21.

http://www.economics.strath.ac.uk/Research/Discussion_papers/discussion_papers.html

National Statistics (2001) UK National Accounts 2001 (The Blue Book 2001).

National Statistics (2002) 'Methodologies for estimating the levels of atmospheric emissions arising from the production of goods imported into the UK', available to download at http://www.statistics.gov.uk/about/methodology_by_theme/Environmental_Accounts/downloads/ Emissions_production_imports.pdf

Richardson, H.W. (1985) 'Input-output and economic base multipliers: looking backward and forward', Journal of Regional Science, Vol.25, No.4, pp607-661. 
Round, J.I. 'Nonsurvey techniques: a critical review of the theory and the evidence', International Regional Science Review, Vol.8, No.3, pp189-212.

Salway, A.G., T.P. Murrells, S. Pye, J. Watterson and R. Milne (2001) 'Greenhouse Gas Inventories for England, Scotland, Wales and Northern Ireland: 1990, 1995, 1998 and 1999', report by AEA Technology.

States of Jersey (1995) '2000 and beyond', Policy and Resources Committee Annual Strategic Policy Review, 1995.

States of Jersey (1998) 'Jersey in the new millenium: a sustainable future' (Policy and Resources Committee consultation document).

Turner, K. (2002) 'Modelling the impact of policy and other disturbances on sustainability policy indicators in jersey: an economic-environmental regional computable general equilibrium analysis', Ph.D. thesis, University of Strathclyde.

Turner, K. (2003) 'A pilot study on constructing a Scottish sectoral $\mathrm{CO}_{2}$ emissions account', Quarterly Economic Commentary (Fraser of Allander Institute, University of Strathclyde), Vol. 28, No.3.

Van den Bergh, J.C.J.M. and Verbruggen, H. (1999) 'Spatial Sustainability, Trade and Indicators: An Evaluation of the 'Ecological Footprint', Ecological Economics, Vol. 29, pp.61-72.

Vaze, P. (1997) 'Environmental input-output tables for the United Kingdom', Economic Trends, No. 527, October 1997.

Vaze, P. (1999) 'A NAMEA for the UK', Structural Change and Economic Dynamics, Vol.10, pp15-37.

Wackernagel, M. and Rees, W. (1996) Our Ecological Footprint: Reducing Human Impact on the Earth, New Society Publishers, Canada. 
Wackernagel, M. and Rees, W. (1997) 'Perceptual and Structural Barriers to Investing in Natural Capital: Economics from an Ecological Footprint Perspective', Ecological Economics, Vol. 21, pp.3-24.

Weir, M. (1998) 'Sources of changes in emissions from energy: a structural decomposition analysis', Economic Systems Research, Vol. 10, No.2, pp.99-112. 
Table 1. Different Types of Fuels Used In Jersey

\begin{tabular}{|c|c|c|c|}
\hline & $\begin{array}{l}\text { Energy/fuel type } \\
\text { Electricity }\end{array}$ & & $\begin{array}{l}\text { Type of use } \\
\text { Heating/lighting }\end{array}$ \\
\hline Gas, Oil \& Fuel Distribution: & $\begin{array}{l}\text { Coal } \\
\text { Gas }\end{array}$ & & $\begin{array}{l}\text { Heating } \\
\text { Heating }\end{array}$ \\
\hline & Oil: & $\begin{array}{l}\text { Standard grade kerosene } \\
\text { Gas oil } \\
\text { Light fuel oil } \\
\text { Heavy fuel oil } \\
\text { Low sulphur kerosene } \\
\text { Petrol/derv }\end{array}$ & $\begin{array}{l}\text { Heating } \\
\text { Heating/electricity generation } \\
\text { Heating } \\
\text { Electricity generation } \\
\text { Greenhouse } \mathrm{CO} 2 \text { enrichment } \\
\text { Automotive }\end{array}$ \\
\hline
\end{tabular}

Table 2. Non-fuel-combustion sources of emissions

\begin{tabular}{|l|l|l|}
\hline Sector & Process & Pollutants \\
\hline Public Services & Waste incineration & $\begin{array}{l}\text { Carbon dioxide (CO2) } \\
\text { Methane (CH4) } \\
\text { Nitrous oxides (NOX) } \\
\text { Non-methane volatile organic compounds (NMVOC) } \\
\text { Carbon monoxide (CO) }\end{array}$ \\
\hline $\begin{array}{l}\text { Manufacturing } \\
\text { Other Service Activities }\end{array}$ & Solvent use & Non-methane volatile organic compounds (NMVOC) \\
\hline $\begin{array}{l}\text { Agriculture \& Fishing } \\
\text { Households } \\
\text { Tourists }\end{array}$ & Biological & Methane (CH4) \\
\hline
\end{tabular}


Table 3 Jersey-Specific Sectoral Emission Intensities - kg/£1mill. Output/Expenditure

\begin{tabular}{|c|c|c|c|c|c|c|c|c|}
\hline Pollutant & $\begin{array}{l}\mathrm{CO}_{2} \text { as } \\
\text { carbon }\end{array}$ & $\mathrm{CH}_{4}$ & $\mathrm{SO}_{2}$ & $\mathrm{NO}_{\mathrm{x}}$ & NMOVOC & $\mathrm{CO}$ & $\mathrm{N}_{2} \mathrm{O}$ & $\begin{array}{l}\text { Black } \\
\text { smoke }\end{array}$ \\
\hline \multicolumn{9}{|l|}{ Production Sectors: } \\
\hline Agriculture \& Fishing & 262119 & 14010.89 & 5419.75 & 2244.17 & 265.85 & 1158.91 & 1.41 & 0.00 \\
\hline Quarrying \& Construction & 30841 & 1.17 & 14.03 & 102.77 & 45.22 & 125.01 & 0.69 & 0.00 \\
\hline Manufacturing & 58068 & 3.33 & 662.05 & 339.26 & 122.70 & 664.80 & 0.50 & 0.00 \\
\hline Electricity & 1310790 & 3.65 & 9500.40 & 17312.43 & 237.17 & 938.18 & 0.18 & 1153.55 \\
\hline Water & 12864 & 2.56 & 0.00 & 62.76 & 93.03 & 547.54 & 0.26 & 0.00 \\
\hline Gas, oil \& fuel distribution & 61380 & 9.43 & 0.00 & 450.46 & 333.29 & 1809.99 & 1.34 & 0.00 \\
\hline Jersey Telecommunications & 5372 & 0.55 & 0.67 & 17.07 & 20.59 & 107.04 & 0.12 & 0.00 \\
\hline Wholesale \& Retail Trade & 24447 & 4.72 & 12.64 & 166.76 & 168.95 & 992.62 & 0.43 & 0.00 \\
\hline estaurants \& Catering & 43706 & 1.98 & 134.56 & 212.42 & 76.12 & 428.97 & 0.15 & 0.00 \\
\hline Land Transport & 62988 & 12.21 & 16.89 & 392.77 & 439.21 & 2569.73 & 1.20 & 0.00 \\
\hline Sea \& Air Transport \& Trans. Supp. & 278158 & 20.52 & 260.83 & 5105.39 & 1432.35 & 4211.77 & 0.21 & 279.53 \\
\hline Post & 13973 & 0.34 & 23.91 & 48.68 & 13.82 & 35.04 & 0.23 & 0.00 \\
\hline Banks \& Bu & 80 & 0.00 & 0.31 & 0.40 & 0.10 & 0.62 & 0.00 & 0.00 \\
\hline Insu & 2732 & 1.19 & 0.00 & 14.63 & 43.29 & 277.79 & 0.03 & 0.00 \\
\hline Investment Trusts \& Fund Managers & 3734 & 1.28 & 3.13 & 19.52 & 46.57 & 298.30 & 0.04 & 0.00 \\
\hline Computer Services & 14153 & 5.33 & 0.84 & 70.00 & 194.46 & 1236.98 & 0.20 & 0.00 \\
\hline ctivities & 3241 & 0.69 & 0.00 & 12.02 & 25.26 & 152.82 & 0.06 & 0.00 \\
\hline Accountancy & 633 & 0.28 & 0.00 & 3.39 & 10.04 & 64.40 & 0.01 & 0.00 \\
\hline Othe & 10652 & 2.00 & 0.00 & 38.39 & 73.53 & 433.55 & 0.22 & 0.00 \\
\hline Other & 74193 & 11.26 & 722.10 & 339.17 & 415.86 & 2452.31 & 1.22 & 0.00 \\
\hline Recreation, Culture \& Sport & 37432 & 1.47 & 68.45 & 142.68 & 58.56 & 300.66 & 0.20 & 0.00 \\
\hline Edu & 20468 & 0.13 & 45.43 & 79.05 & 7.55 & 12.22 & 0.05 & 0.00 \\
\hline Health, Social Work \& Housing & 23733 & 0.14 & 35.54 & 83.68 & 9.31 & 12.96 & 0.04 & 0.00 \\
\hline Public Services & 568032 & 128.27 & 29.49 & 3572.08 & 10396.98 & 41820.54 & 0.03 & 0.00 \\
\hline Public Adminstration \& Defence & 6200 & 0.04 & 2.21 & 18.54 & 2.69 & 2.99 & 0.00 & 0.00 \\
\hline \multicolumn{9}{|l|}{ Final Demand Categories } \\
\hline Household Incor & 112639 & 270.68 & 206.57 & 464.29 & 1389.40 & 8117.86 & 0.93 & 0.00 \\
\hline Household Income Group 2 & 142900 & 192.07 & 139.49 & 633.20 & 2008.86 & 11854.93 & 1.40 & 0.00 \\
\hline Household Income Group 3 & 123173 & 149.61 & 194.58 & 549.74 & 1797.62 & 10562.63 & 1.23 & 0.00 \\
\hline Household Income Group 4 & 115040 & 118.83 & 105.55 & 512.29 & 1626.96 & 9602.24 & 1.14 & 0.00 \\
\hline Household Income Group 5 & 110763 & 89.84 & 43.93 & 464.59 & 1343.32 & 7957.27 & 0.96 & 0.00 \\
\hline Tourists & 38028 & 56.50 & 0.00 & 189.90 & 663.54 & 3949.68 & 0.48 & 0.00 \\
\hline
\end{tabular}


Table 4 UK-Adjusted Sectoral Emission Intensities for Jersey - $\mathbf{k g} / \mathbf{£ 1 m i l l . ~ O u t p u t / E x p e n d i t u r e ~}$

\begin{tabular}{|c|c|c|c|c|c|c|c|}
\hline Pollutant & $\begin{array}{l}\mathrm{CO}_{2} \text { as } \\
\text { carbon }\end{array}$ & $\mathrm{CH}_{4}$ & $\mathrm{SO}_{2}$ & $\mathrm{NO}_{\mathrm{x}}$ & NMOVOC & $\mathrm{CO}$ & $\mathrm{N}_{2} \mathrm{O}$ \\
\hline \multicolumn{8}{|l|}{ Production Sectors: } \\
\hline Agriculture \& Fishing & 81554 & 45639.38 & 461.23 & 2535.91 & 798.97 & 3633.16 & 4430.08 \\
\hline Quarrying \& Construction & 17696 & 10.04 & 45.15 & 577.39 & 661.96 & 2831.31 & 16.26 \\
\hline Manufacturing & 34122 & 7.95 & 179.10 & 315.55 & 1535.91 & 174.18 & 2.27 \\
\hline Electricity & 1477975 & 677.47 & 38787.26 & 13239.63 & 277.69 & 2987.62 & 235.55 \\
\hline Water & 38454 & 10.19 & 46.51 & 611.91 & 710.35 & 2492.16 & 14.72 \\
\hline Gas, oil \& fuel distribution & 22635 & 9698.62 & 7.63 & 263.61 & 2302.70 & 921.68 & 2.98 \\
\hline Jersey Telecommunications & 11231 & 4.21 & 7.87 & 169.20 & 83.28 & 530.92 & 1.89 \\
\hline Wholesale \& Retail Trade & 17627 & 6.82 & 11.32 & 337.05 & 147.84 & 862.98 & 3.33 \\
\hline Hotels, Restaurants \& Catering & 12767 & 4.34 & 3.25 & 106.86 & 60.95 & 461.01 & 1.43 \\
\hline Land Transport & 247043 & 69.61 & 206.22 & 6969.05 & 1527.27 & 5310.51 & 33.34 \\
\hline Sea \& Air Transport \& Trans. Supp. & 293542 & 140.94 & 5142.68 & 10293.17 & 1719.14 & 4028.01 & 47.13 \\
\hline Post & 11231 & 4.21 & 7.87 & 169.20 & 83.28 & 530.92 & 1.89 \\
\hline Banks \& Building Societies & 8638 & 3.31 & 5.39 & 93.26 & 62.66 & 492.91 & 1.48 \\
\hline Insurance Companies & 8694 & 3.49 & 4.71 & 101.04 & 69.93 & 551.90 & 1.64 \\
\hline Investment Trusts \& Fund Managers & 8174 & 3.03 & 5.37 & 83.21 & 54.56 & 428.09 & 1.29 \\
\hline Computer Services & 13079 & 5.96 & 10.79 & 196.87 & 220.67 & 1139.36 & 3.39 \\
\hline Legal Activities & 8422 & 2.98 & 7.09 & 81.08 & 51.28 & 399.88 & 1.22 \\
\hline Accountancy & 8422 & 2.98 & 7.09 & 81.08 & 51.28 & 399.88 & 1.22 \\
\hline Other Business Activities & 9214 & 3.72 & 7.16 & 122.81 & 78.97 & 596.99 & 1.85 \\
\hline Other Services Activities & 16856 & 6.43 & 13.84 & 248.56 & 761.15 & 908.26 & 3.09 \\
\hline Recreation, Culture \& Sport & 11683 & 3.03 & 48.14 & 82.74 & 35.68 & 261.92 & 1.10 \\
\hline Education & 29057 & 6.62 & 85.31 & 165.14 & 66.32 & 502.90 & 2.04 \\
\hline Health, Social Work \& Housing & 13297 & 2.77 & 116.87 & 65.96 & 31.49 & 93.62 & 0.55 \\
\hline Public Services & 30634 & 110683.65 & 53.66 & 1250.81 & 1324.95 & 723.43 & 76.85 \\
\hline Public Adminstration \& Defence & 35633 & 6.32 & 213.64 & 580.11 & 34.33 & 187.55 & 2.73 \\
\hline $\begin{array}{l}\text { Final Demand Categories } \\
\text { Households }\end{array}$ & $\begin{array}{r}0 \\
74265\end{array}$ & 91.37 & 116.45 & 900.20 & 1049.63 & 5500.41 & 18.21 \\
\hline
\end{tabular}


Table 5. Environmental accounting: total emissions $(\mathrm{kg})$ of 7 air pollutants generated in Jersey 1998

\begin{tabular}{|l|c|c|}
\hline \multirow{2}{*}{} & Estimates based on: \\
\cline { 2 - 3 } & Jersey-specific data & UK-adjusted data \\
POLLUTANTS: & Equation 7 & Equation 8 \\
\hline $\mathrm{CO}_{2}$ as carbon & $291,065,182$ & $215,481,253$ \\
$\mathrm{CH}_{4}$ & 961,262 & $5,826,417$ \\
$\mathrm{SO}_{2}$ & $1,024,795$ & $2,403,697$ \\
$\mathrm{NO}_{\mathrm{X}}$ & $2,205,893$ & $3,127,692$ \\
$\mathrm{NMVOC}$ & $2,403,511$ & $1,874,431$ \\
$\mathrm{CO}$ & $13,277,245$ & $\mathbf{8 , 4 3 9 , 3 8 2}$ \\
$\mathrm{N}_{2} \mathrm{O}$ & 1,933 & 295,809 \\
\hline
\end{tabular}

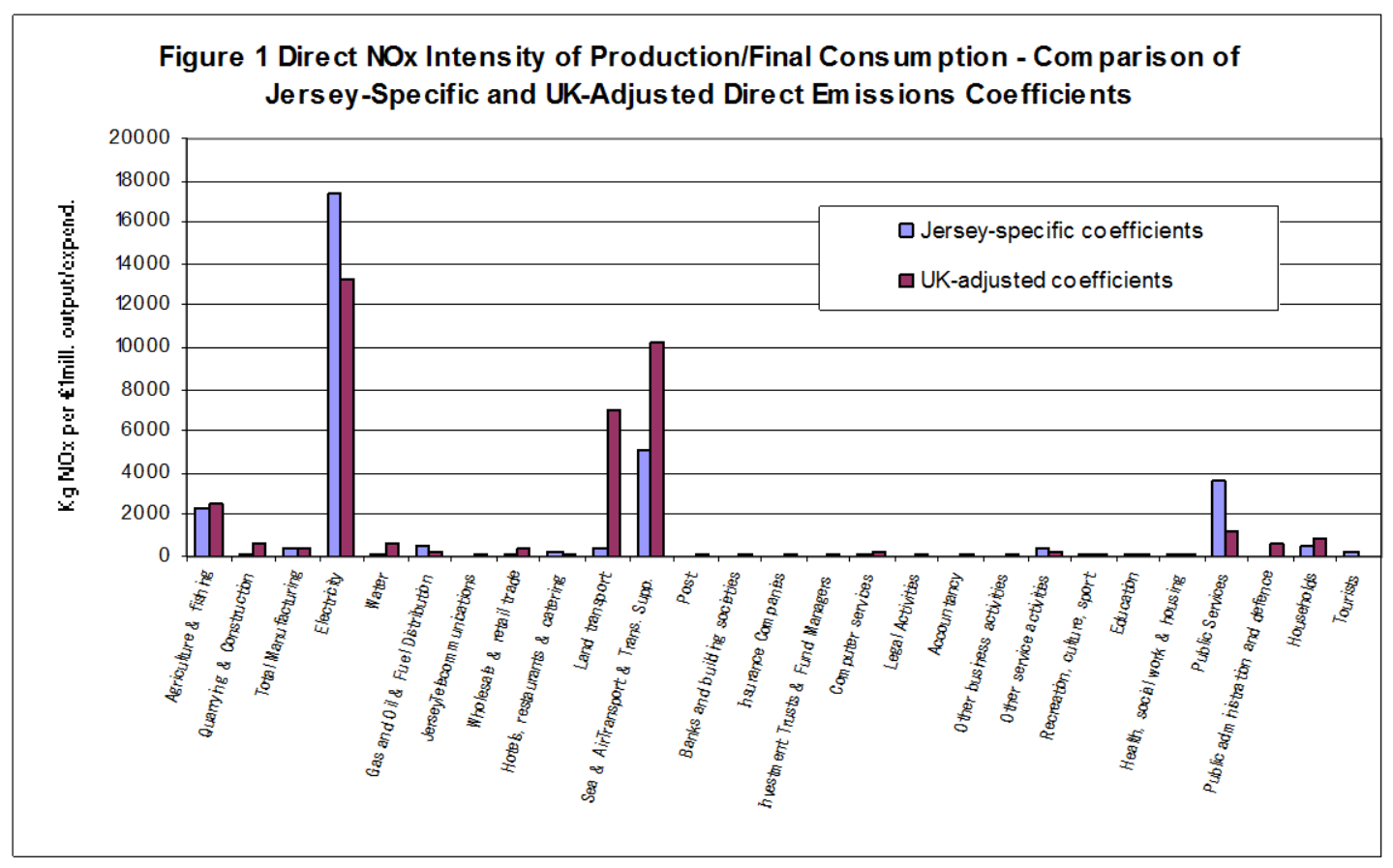



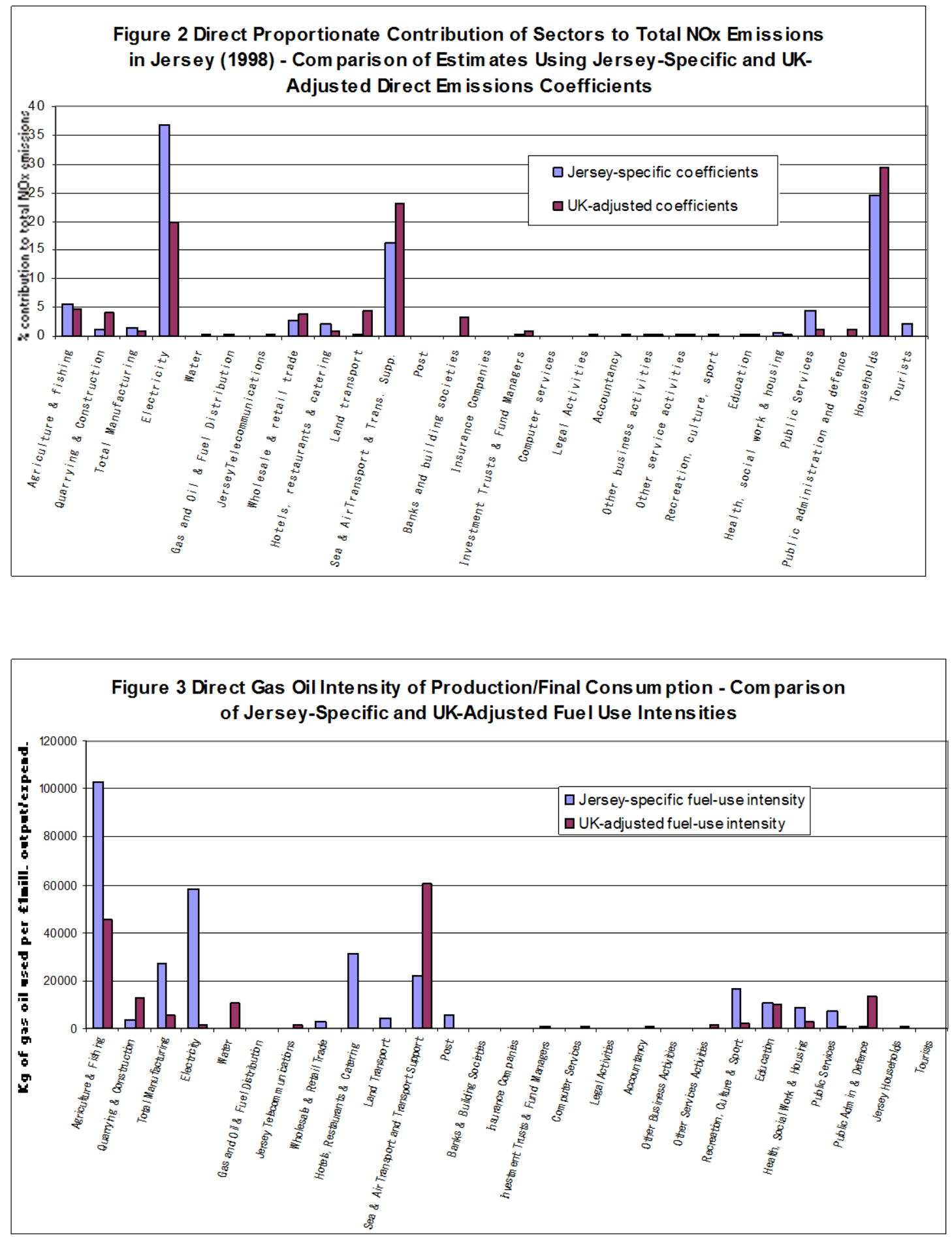


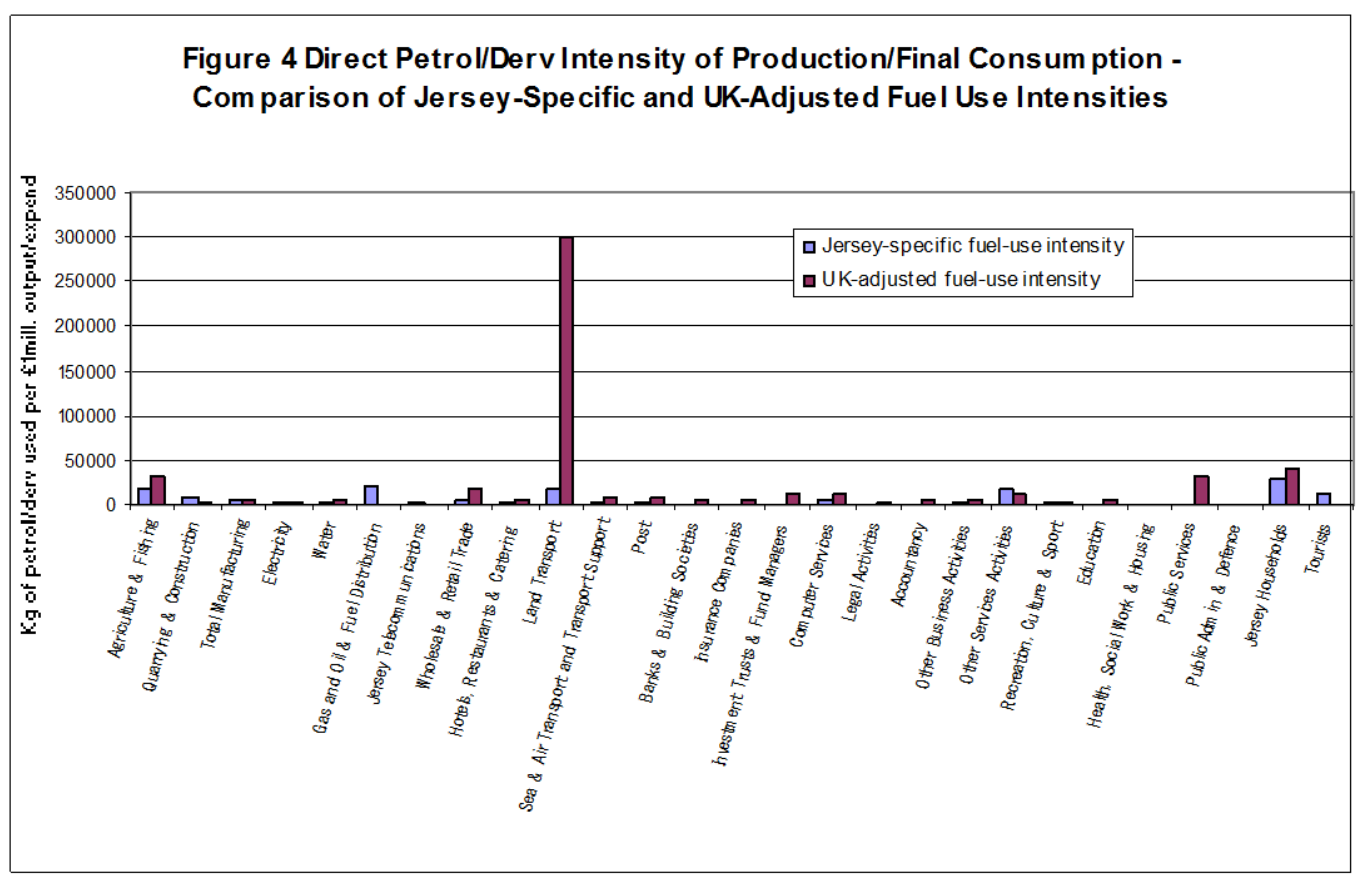

